\title{
Mixed Phase Anatase/rutile Titanium Dioxide Nanotubes for Enhanced Photocatalytic Degra- dation of Methylene-blue
}

\author{
Mario Boehme*, Wolfgang Ensinger
}

(Received 15 October 2011; accepted 23 November; published online 19 December 2011).

\begin{abstract}
Titanium dioxide Nanotubes (TNTs) prepared by electroless deposition have been annealed at air ambient and low temperature. As a result, the anatase/rutile phase composition of the TNTs can be tailored to the needs of later applications. Nanotubes with anatase/rutile mixed phase ratio of 4:1 have been produced in this report and further examined for their photocatalytical behavior. The photocatalytical properties of the TNTs have been observed by degradation of methylene-blue in aqueous solution under low power UV-light irradiation. The results shown in this report are based on the synergetic effect between rutile and anatase, which results in the mixed phase $\mathrm{TiO}_{2}$ nanotubes having enhanced photocatalytical properties.
\end{abstract}

Keywords: Electroless deposition; Degussa P25; Nanotubes; Titanium dioxide; Anatase

Citation: Mario Boehme and Wolfgang Ensinger, "Mixed Phase Anatase/rutile Titanium Dioxide Nanotubes for Enhanced Photocatalytic Degradation of Methylene-blue", Nano-Micro Lett. 3 (4), 236-241 (2011). http:// dx.doi.org/10.3786/nml.v3i4.p236-241

\section{Introduction}

Titanium dioxide nanostructures are currently showing strong significance in science and engineering. Semiconductive materials with suitable band gap and flat band potentials are used as photocatalysts. Several semiconductors such as $\mathrm{TiO}_{2}, \mathrm{ZnO}$ or $\mathrm{Fe}_{2} \mathrm{O}_{3}$ are employed in industrial applications [1]. In case of photocatalytic nanomaterials, anatase titanium dioxide is the most widely used photocatalyst, pursuant to its pivotal role in photochemical solar cells with high conversion efficiency, due to its large band gap from $3.2 \mathrm{eV}$, corresponding to $387 \mathrm{~nm}[2-7]$.

There are two forms of $\mathrm{TiO}_{2}$ - antase and rutile which are frequently studied [8], where the rutile modification of $\mathrm{TiO}_{2}$ is known as the "photocatalytical less" active form.

For anatase titanium dioxide nanostructures, miscellaneous methods such as electro-spinning, sol-gel method or chemical vapor condensation, have been developed and applied [9-12]. $\mathrm{TiO}_{2}$ nanotube template based sol-gel method has been developed successfully [13]. Further on self-aligned, highly ordered $\mathrm{TiO}_{2}$ nanotube arrays has been produced by potentiostatic anodization of titanium foil [14]. Additionally a direct preparative method of anatase $\mathrm{TiO}_{2}$ nanotubes in porous alumina membranes has been reported earlier [15]. In our previous report, we described for the first time the synthesis of anatase titanium dioxide nanotubes (TNTs) by electroless deposition, under aqueous conditions in ion track etched polycarbonate templates [16]. These anatase titanium dioxide nanotubes have been synthesized having a diameter of approx. $100 \mathrm{~nm}$ and a wall thickness of approx. $10 \mathrm{~nm}$.

As has been shown previously, that mixtures of anatase and rutile show synergetic effects between both phases [17]. Positive interactions between the rutile and the anatase phase of $\mathrm{TiO}_{2}$ have been reported additionally within other systems $[18,19]$. Further more, synergetic effects and charge separations between $\mathrm{TiO}_{2}$

\footnotetext{
${ }^{1}$ Department of Materials Science, Darmstadt University of Technology, Petersen Str. 23, 64287 Darmstadt, Germany

*Corresponding author. E-mail: mboehmeca.tu-darmstadt.de
} 
and other materials have been discussed in literature [20-23].

In our previous work, we mentioned that it would be very interesting and useful to control the quantity of anatase and rutile phase of the TNTs. The phase reaction between the meta stable anatase phase and the stable rutile phase has considerable importance. It has been shown, that nano-crystalline $\mathrm{TiO}_{2}$ could be phase selected using careful control of the particle size and other experimental conditions, such as temperature [24-26]. To date, just a few reports have been published, which refer to this transformation and most of them perform their transformation research in regions above $800 \mathrm{~K}[27,28]$. The level of phase transformation depends on different parameters, such as initial phase, reacting ambience, annealing temperature, and particle size [29-31].

With this report, we continue our work [16] and report the results of our studies about the anatase to rutile phase transformation of anatase $\mathrm{TiO}_{2}$-nanotubes, generated using electroless deposition at room temperature, followed by annealing at temperatures below $600 \mathrm{~K}$ to achieve mixed phase TNTs. Further more, we studied the photocatalytic degradation behavior of the synthesized mixed phase TNTs, using methylene-blue ambience in the way of a known procedure to compare the results [32].

\section{Experimental Section}

\section{Sample preparation}

The preparation of the TNTs was described in detail previously [16]. Therefore we present here an overview on the template based preparation process. The template consists of a polycarbonate foil having a thickness of 6 to $30 \mu \mathrm{m}$. The foil was chemically etched to achieve a template with a pore diameter of approx. $80 \mathrm{~nm}$. Prior to the electroless deposition process, the surface of the polycarbonate template was treated with sensitization and activation solutions. To obtain titanium dioxide nanostructures, preferably titanium dioxide nanotubes, the sensitized and activated template was dipped into an aqueous solution containing $\mathrm{Ti}_{2}$ $\left(\mathrm{SO}_{4}\right)_{3}$ and $\mathrm{C}_{2} \mathrm{H}_{8} \mathrm{BN}$. The time of deposition can be varied regarding to the desired wall thickness. In this work, the deposition time was 12 minutes with the result of $\mathrm{TiO}_{2}$ nanotubes with 10-12 nm wall thickness, shown in the SEM pictures in Fig. 1.

After the deposition process, the polycarbonate was removed easily, using 1,2-dichloromethane. The 1,2-dichloromethane incorporated the polycarbonate, and the TNTs remain as a suspension. Using centrifugation the TNTs were separated from the 1,2dichloromethane, which was removed and replaced with fresh solvent. This procedure was repeated a min- imum of 15 times, to ensure that all polycarbonate was removed. After the last centrifugation, the 12-dichloromethane standing over TNTs in the hydroextracted suspension, was removed as much as possible. The TNTs were now being placed on a heat resistant flat surface, e.g. a small piece of a silicon wafer, where the remaining 1-2-dichloromethane was evaporated at ambient air. After the TNTs were dried, the substrate carrying the TNTs was placed into a tubular furnace where the TNTs were annealed at $583^{\circ} \mathrm{K}$; and ambient air at normal pressure for different short term ranges.
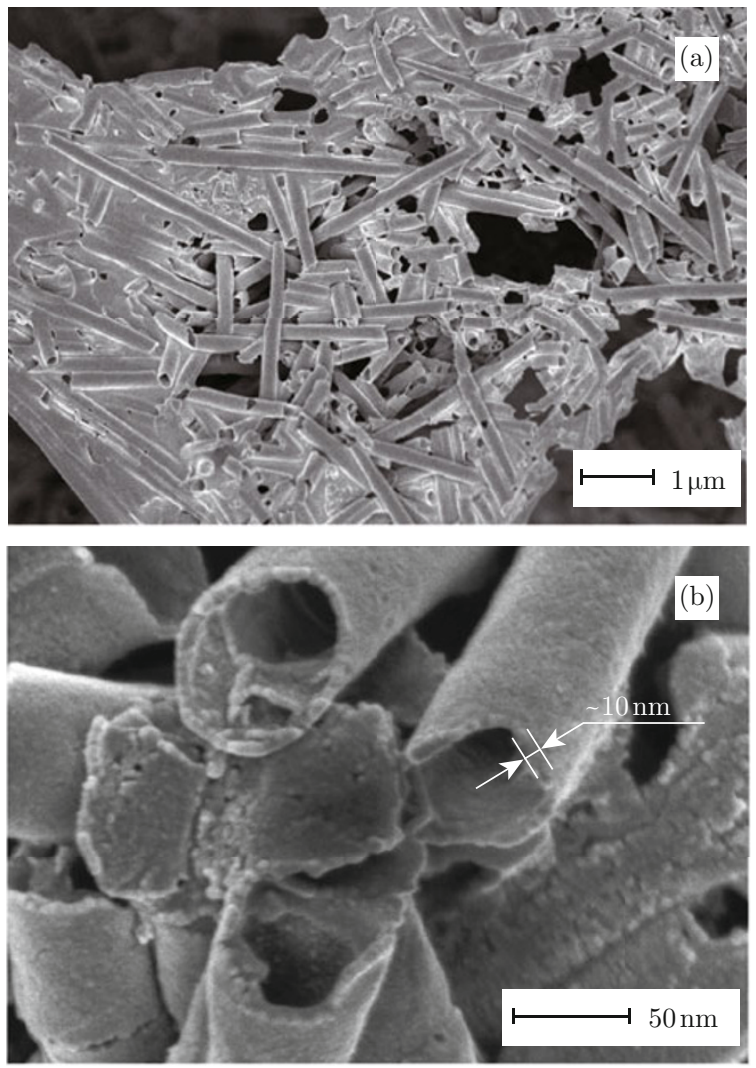

Fig. 1 (a) SEM picture of $\mathrm{TiO}_{2}$ nanotubes unhinged from the polycarbonate template, (b) SEM picture close up of some nanotubes showing their thin walls.

\section{Characterization}

After the deposition process, scanning electron microscopy (SEM) was used for morphology and size distribution investigations of the nanostructures. To get structural information about the phase transformation of the TNTs, the crystalline phase of titanium dioxide was studied by X-Ray Diffraction (XRD) using Mo $\mathrm{K} \alpha(\lambda=71,07 \mathrm{pm})$ radiation. A $2 \Theta$ range of $5^{\circ}$ to $45^{\circ}$ was scanned with a step of $0.02^{\circ}$ using an integration time of 3 seconds. To assure to have sufficient nanotubes for later X-Ray diffraction and degradation studies, around 20 templates have been prepared for each X-Ray diffraction analysis. For the photocatalytic methylene-blue degradation study we used UV- 
VIS spectroscopy (Lambda 900 PerkinElmer) at a scanning wavelength range from 400-800 $\mathrm{nm}$.

\section{Photocatalytic activity measurement}

It is well understood that the photocatalytic dyes' degradation rate under UV-light irradiation is significantly higher than those under solar light [33]. Due to the degradation efficiency and the time saving manner following thereof, the photocatalytic activity of the TNTs was evaluated by the degradation of aqueous methylene-blue under illumination of UV-light. Regarding the previous reports on the enhanced photocatalytic behavior of mixed phase $\mathrm{TiO}_{2}$, the photocatalytic activity measurement of the produced TNTs was examined after calcinations, having a rutile/anatase ratio of $1: 4$.

The cleaned and annealed TNTs were suspended in $2 \mathrm{ml}$ of an aqueous methylene-blue solution containing $4.2 \mathrm{mg} / \mathrm{l}$ methylene-blue dye, $1.3 \times 10^{-5} \mathrm{~mol} / \mathrm{L}$ respectively; having a $\mathrm{pH}$ of 2 and were ready for photocatalytical testing after sonication of approximated 5 minutes. Yao et al. observed that the photodegradation efficiency decreases in the order of $\mathrm{pH} 2>\mathrm{pH} 9>\mathrm{pH} 7$ and got best results for photodecradation at $\mathrm{pH} 2$ [34]. Based on literature reports, best results for photocatalytic degradation of methylene-blue have been shown with dye concentrations of about $3.12 \times 10^{-5} \mathrm{~mol} / \mathrm{l}$ in reference to a photocatalyst concentration of around $1 \mathrm{~g} / \mathrm{l}[1]$. Due to the low weight of the TNTs and by keeping reference to literature results vis-a-vis the achieved results of this report - a dye concentration of $1.3 \times 10^{-5} \mathrm{~mol} / \mathrm{l}$ and five polycarbonate templates containing the TNTs were used for each photocatalytic dye degradation sample. Because of the wall thickness of the TNTs from about $10 \mathrm{~nm}$, the template thickness of $30 \mu \mathrm{m}$ and the tube density of $1 \times 10^{8}$ tubes $/ \mathrm{cm}^{2}$, the used photocatalyst concentration was about $0.40 \mathrm{~g} / \mathrm{l}$ by using the nanotubes of five template foils with an area of $4.9 \mathrm{~cm}^{2}$ each in a total suspension volume of $2 \mathrm{ml}$. The light source was based on six single UV-light emitting tubes, placed parallel next to each other with a distance of $3 \mathrm{~cm}$, having a predominant wavelength of $315 \mathrm{~nm}$ and total power of $54 \mathrm{~W}$. The test vials containing methylene-blue solution and TNTs were placed in the same condition in the homogenous emitting area of the light source. The distance from the vials to the light source was around $20 \mathrm{~cm}$. With regard to the vials' irradiation exposed surface area, the relative irradiation power was $50 \mathrm{~mW} / \mathrm{cm}^{2}$ for each vial.

\section{Results and Discussion}

\section{Rutil/Anatase phase transformation}

In the past there have been several studies on the photocatalytic activity of anatase- $\mathrm{TiO}_{2}$. In the early 1990's, Bickley, et al. [35] proposed the hypothesis of enhanced photocatalytic activity of mixed phase $\mathrm{TiO}_{2}$ relative to pure phase $\mathrm{TiO}_{2}$. Since then a mixed phase $\mathrm{TiO}_{2}$ powder is sold as the Degussa P25 photocatalyst. There have been a lot of reports within the past few years, pointing out the enhanced photocatalytic activity of the Degussa P25. Later, the P25 was investigated by Hurum et al. [36] to explain the reason of this enhancement. As a result, it has been well documented that there is an enhancement of $\mathrm{TiO}_{2}$ photocatalysis, having a rutile/anatase mixed phase ratio of 1:4 [37].

For this reason, we have studied the phase transformation of our produced anatase TNTs [16] to tailor the performance of the nanotubes, in order to reach the optimum, mixed phase concentrations, resulting in the best of photocatalytic activity.

The effect of annealing the anatase $\mathrm{TiO}_{2}$ nanotubes at $583 \mathrm{~K}$ and air ambient at normal pressure for different short term ranges can be observed in Fig. 2.

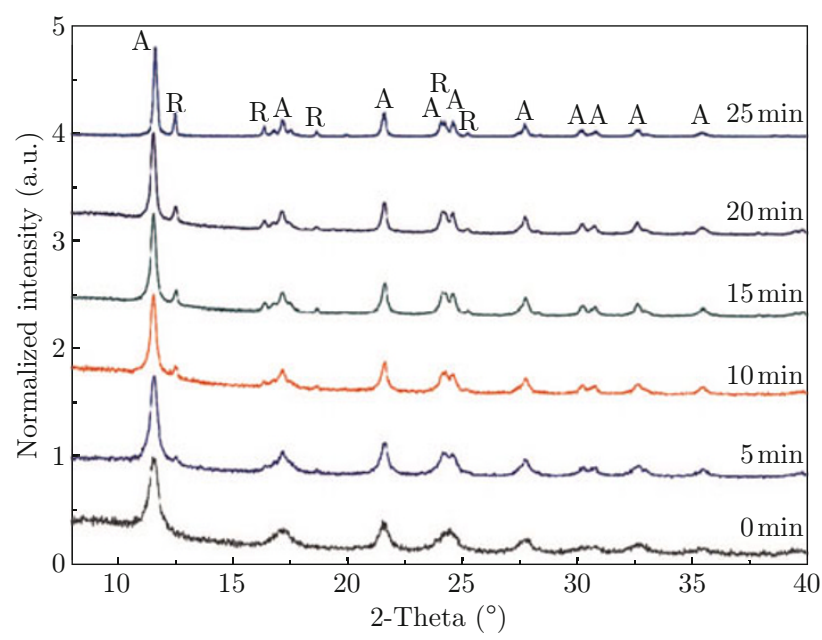

Fig. 2 XRD diffraction patterns of the annealed $\mathrm{TiO}_{2}-$ nanotubes showing the different heat exposure times; $\mathrm{R}=$ Rutile and $\mathrm{A}=$ Anatase

The weight fraction of the formed rutile and anatase ratio in the nanotubes during the different calcination times have been determined by computer, based on the equation described by Spurr and Myers [38]

$$
x_{a}=\frac{100}{1+\left(\frac{I_{R}}{0.79 I_{A}}\right)}
$$

where $\mathrm{x}_{\mathrm{A}}$ is the weight fraction of the anatase $\mathrm{TiO}_{2}$ phase in the produces TNTs, while $\mathrm{I}_{\mathrm{R}}$ and $\mathrm{I}_{\mathrm{A}}$ are equivalent to the relative reflection intensities of rutile and anatase.

The calculated anatase/rutile ratio as well as the corresponding calcination time are shown in the diagram of Fig. 3. The diagram displays that the phase compounds of the thin walled TNTs can be varied and tailored to the need of the structures that are later used for. Due to the previous reported optimal rutile/anatase ratio 


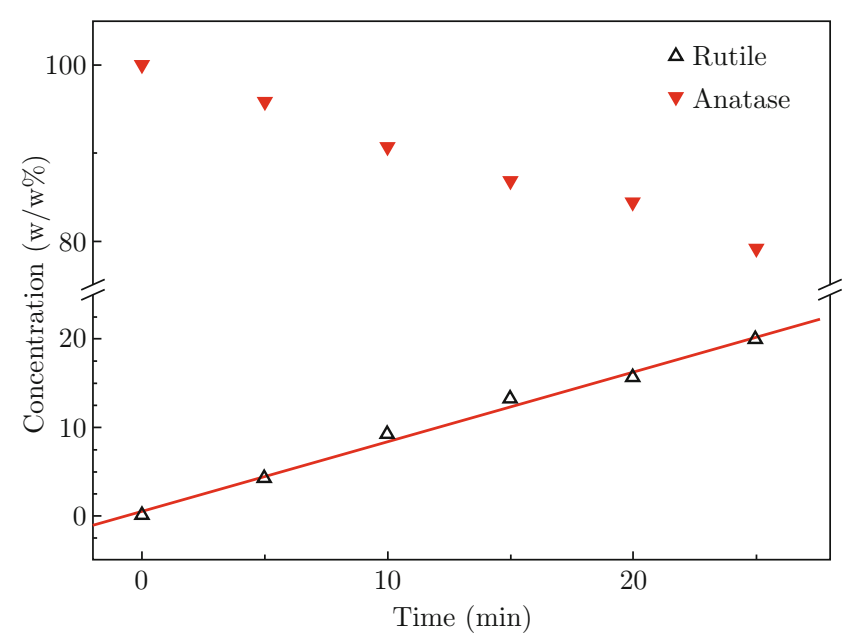

Fig. 3 Calcination time and resulting anatase/rutile ratio present in the $\mathrm{TiO}_{2}$ nanotubes at an annealing temperature of $583^{\circ} \mathrm{K}$ at air ambient.

for photocatalysis, we stopped the annealing experiments after achieving the reported ratio of 1:4 with 25 minutes of calcination.

It has been shown that anatase to rutile phase transformation is taking place inside nanostructures, even at lower temperatures of just $583 \mathrm{~K}$, that are far below temperature of around $800 \mathrm{~K}$ that are reported to date.

\section{Photocatalytic activity}

Figure 4 shows the typical UV-Vis spectrum of methylene-blue having an absorption maximum at $664 \mathrm{~nm}$. In order to observe the photocatalytic activity for the degradation of methylene-blue using mixed phase $\mathrm{TiO}_{2}$ nanotubes, the absorbance was measured at a time interval of 10 minutes. The colour of methyleneblue after adding the photocatalyst was blue under dark conditions. The results in Fig. 5 are showing that the degradation of methylene-blue in an absence of the photocatalyst under irradiation was nearly $10 \%$ at the end of the measurements. While in the case of presence of the mixed phase $\mathrm{TiO}_{2}$ nanotubes complete degradation takes place. Within the total of 80 minutes irradiation time the colour of the methylene-blue/nanotube suspension changed from deep blue to milky white. According to the absorption spectra in Fig. 4 after 80 minutes UV-light irradiation, nearly the total amount of methylene-blue was degraded.

The degradation vs. time curve in Fig. 5 is showing continuously a higher slope with longer irradiation time and higher degradation level. We are with the opinion that this effect is resulting in the changing relation of the continuous delivery of oxidation radicals from the irradiated nanotubes with the continuously lowered concentration of oxidizable methylene-blue molecules. In comparison of other work using $\mathrm{TiO}_{2} /$ methylene-blue degradation systems based on nanoparticles $[1,34]$ the modified $\mathrm{TiO}_{2}$ nanotubes of this report are showing a

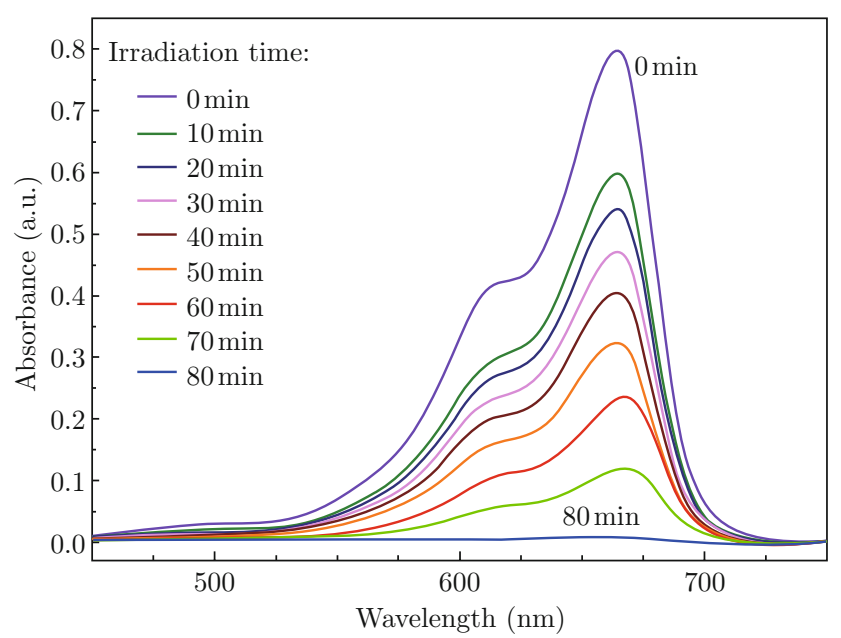

Fig. 4 UV-Vis spectra of methylene-blue degradation after treatment with mixed phase $\mathrm{TiO}_{2}$ nanotubes.

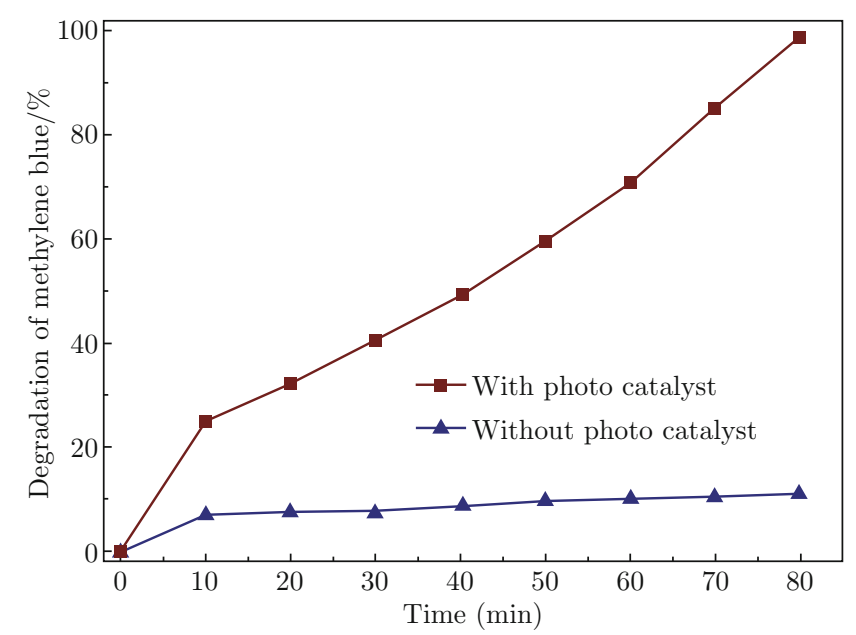

Fig. 5 Effect of methylene-blue degradation using mixed phase $\mathrm{TiO}_{2}$ nanotubes.

minimum of $50 \%$ shorter degradation time, using a lower irradiation power with a consideration on the used dye concentration.

Based on the Model of an rutile antenna proposed by Hurum et al. some years ago, mixed phase titania can achieve efficient intergranular charge transfer to enhance the photoactivity predicated on charge separation [36]. The band charge diagram proposed by this model is shown in Fig. 6 (a). The prepared mixedphase TNTs show a higher photo- catalytic activity when compared to mixed particle rutile/anatase based photocatalysts. We assume that the enhancement can be attributed to the nano-sized mixed phase clusters inside the ultra-thin TNT walls. The rutile functions as a receiver to modify the photoresponse of anatase to longer wave-lengths and additionally enhances the photoefficiency by decreasing the recombination rate of generated charges.

Due to the long distance the photo-generated charges 


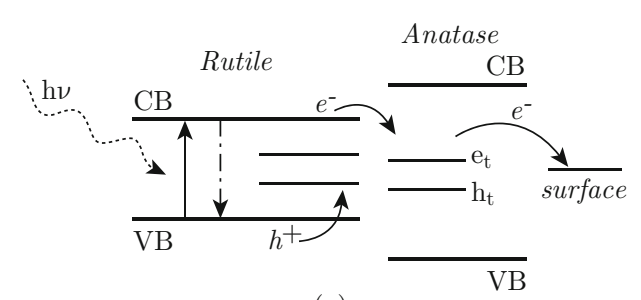

(a)
Partikel based

mixed-phase photocatalyst

(b)

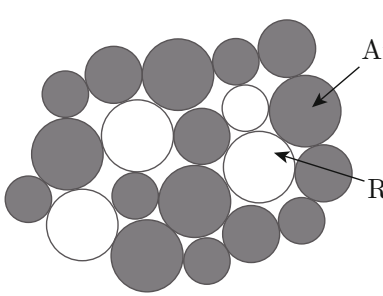

Nanotube based

mixed-phase photocatalyst
Fig. 6 (a) Band charge diagram of mixed phase TNTs with rutile working as an photonic antenna. Illustration of the rutile/anatase contact area to compare particle based (b) and nanotube based (c) mixed phase photo catalysts.

have to travel before reaching an attractive anatase particle, illustrated in Fig. 6 (b), these system have high recombination rates and the rutile phase in a particle based mixed phase photocatalyst is rarely active. Inside the tailored ultra-thin walled TNTs, illustrated in Fig. 6 (c), the photo generated charges can be transferred fast, due to short distance based on sub-nano clusters, which prevents rapid recombination. Having a reduced recombination rate, more free electrons will be available. As a result, there is an enhanced amount of photocatalytic activity.

\section{Conclusion}

Selective synthesis of mixed phase $\mathrm{TiO}_{2}$ nanotubes has been performed by electroless deposition of anatase $\mathrm{TiO}_{2}$ nanotubes, followed by a short annealing procedure at $583 \mathrm{~K}$. The phase compounds of the obtained nanotubes can be tailored to the needs of their further application. As reported previously the presence of rutile in anatase photocatalyst will enhance their efficiency. Using particle-sized photocatalyst, this enhancement depends on the relationship between the particle size and the $\mathrm{TiO}_{2}$ phases. In the case of the nanotubes in this report, which have a wall thickness of $10 \mathrm{~nm}$, the wall consists of small sized phase particles. Based on the small dimensions an intimate contact with rutile and anatase, an enhanced catalyst with higher activity is formed. To the best of our knowledge, the developed mixed phase anatase/rutile $\mathrm{TiO}_{2}$ nanotubes are actually showing a very high grade of photocatalytic activity, higher than the reported results of other mixed phase $\mathrm{TiO}_{2}$ catalysts based on nanoparticles.

\section{References}

[1] R. J. Tayade, T. S. Natarajan and H. C. Bajaj, Ind. Eng. Chem. Res. 48, 10262 (2009). http://dx.doi. org/10.1021/ie9012437

[2] M. R. Hoffmann, S. T. Martin, W. Choi and D. W. Bahnemann, Chem. Rev. 95, 69 (1995). http://dx. doi.org/10.1021/cr00033a004

[3] B. Li, X. Wang, M. Yan and L. Li, Mater. Chem. Phys. 78, 184 (2003). http://www.sciencedirect. com/science/article/B6TX4-46SG3DN-4/2/ d7c686b81aaf493c4d2f290a744bc767

[4] A. Fujishima, T. N. Rao and D. A. Tryk, J. Photochem. Photobio. C: Photochem. Rev. 1, 1 (2000). http://www.sciencedirect. com/science/article/B6W79-41R3GCK-2/2/97df01d 046ea84e4d6250e0193e020a1

[5] A. L. Linsebigler, G. Lu and J. T. Yates, Chem. Rev. 95, 735 (1995). http://dx.doi.org/10.1021/ cr00035a013

[6] H. Tada, M. Yamamoto and S. Ito, Langmuir 15, 3699 (1999). http://dx.doi.org/10.1021/la9816712

[7] J. C. Yu, J. Yu and J. Zhao, Appl. Catal. B: Environ. 36, 31 (2002). http://www.sciencedirect. com/science/article/B6TF6-44B6YGW-3/2/ caa0a37cb0941c52b769a0814c1cabd8

[8] L. Kavan, M. Grätzel, S. E. Gilbert, C. Klemenz and H. J. Scheel, J. Am. Chem. Soc. 118, 6716 (1996). http://dx.doi.org/10.1021/ja9541721

[9] D. Li and Y. Xia, Nano Letters 4, 933 (2004). http:// dx.doi.org/10.1021/nl049590f

[10] A. Sadeghzadeh Attar, M. Sasani Ghamsari, F. Hajiesmaeilbaigi, S. Mirdamadi, K. Katagiri and K. Koumoto, J. Mater. Sci. 43, 5924 (2008). http://dx. doi.org/10.1007/s10853-008-2872-y

[11] T. Maiyalagan, B. Viswanathan and U. V. Varadaraju, Bull. Mater. Sci. 7, 3 (2006). http://203.199.213.48/ $52 /$

[12] W. Li, S. Ismat Shah, C. P. Huang, O. Jung and C. Ni, Mater. Sci. Eng. B 96, 247 (2002). http:// WwW.sciencedirect.com/science/article/B6TXF46YXMJ1-1/2/595f05b79496b0458624c7c4ff5a7bdb

[13] T. Maiyalagan, B. Viswanathan and U. V. Varadaraju, Bull. Mater. Sci. 29, 705 (2006). http://203.199.213. 48/52/

[14] M. Paulose, K. Shankar, S. Yoriya, H. E. Prakasam, O. K. Varghese, G. K. Mor, T. A. Latempa, A. Fitzgerald and C. A. Grimes, J. Phys. Chem. B 110, 16179 (2006). http://dx.doi.org/10.1021/jp064020k

[15] H. Imai, Y. Takei, K. Shimizu, M. Matsuda and H. Hirashima, J. Mater. Chem. 9, 2971 (1999). http:// dx.doi.org/10.1039/A906005G

[16] M. Boehme, G. Fu, E. Ionescu and W. Ensinger, Nano-Micro Letters 2, 22 (2010). http:// ww. nmletters . org/index . php? journal=nml \\&page= article $\backslash \& o p=$ view $\backslash \&$ path []$=46$

[17] T. Ohno, K. Sarukawa, K. Tokieda and M. Matsumura, J. Catal. 203, 82 (2001). http://www.sciencedirect. 
com/science/article/B6WHJ-45BCC6C-3G/2/3fe6aa $560 b 59039 f e 084 f 2 b 46 e d 6 d 269$

[18] R. R. Bacsa and J. Kiwi, Appl. Catal. B: Environ. 16, 19 (1998). http://www.sciencedirect. com/science/article/B6TF6-3VN03K2-2/2/58d61c 1a346ba4b25b4155184585c137

[19] K. Tanaka, M. F. V. Capule and T. Hisanaga, Chem. Phys. Lett. 187, 73 (1991). http://www.sciencedirect. com/science/article/ B6TFN-44K955N-2J/2/c4b6c0ff995216d03eb2d99bec f28aaa

[20] G. Blondeel, A. Harriman and D. Williams, Solar Energy Materials 9, 217 http://www.sciencedirect. com/science/article/B7571-481F872-2B/2/749c5e 596ca2041e8ca7f8b743cb31e1

[21] H. Tada, A. Hattori, Y. Tokihisa, K. Imai, N. Tohge and S. Ito, J. Phys. Chem. B 104, 4585 (2000). http:// dx.doi.org/10.1021/jp000049r

[22] T. Kawahara, Y. Konishi, H. Tada, N. Tohge and S. Ito, Langmuir 17, 7442 (2001). http://dx.doi.org/ 10.1021/la010307r

[23] F. Ye and A. Ohmori, Surf. Coat. Tech. 160, 62 (2002). http://www.sciencedirect.com/ science/article/B6TVV-46H7SJB-7/2/a7b863dda08 6 dee2ad8d310cf5e650b6

[24] H. Zhang, M. Finnegan and J. F. Banfield, Nano Letters 1, 81 (2000). http://dx.doi.org/10.1021/ n10055198

[25] T. Sugimoto, X. Zhou and A. Muramatsu, J. Coll. Inter. Sci. 259, 43 (2003). http://www. sciencedirect. com/science/article/B6WHR-480CK3K-J/2/b39fd8 acd70b423260ca1cc5bbf2a53d

[26] S. Kittaka, K. Matsuno and S. Takahara, J. Solid State Chem. 132, 447 (1997). http://www.sciencedirect. com/science/article/B6WM2-45K153M-5V/2/ded00 fb7136b292ced79ceb592dcc450
[27] H. M. Lu, W. X. Zhang and Q. Jiang, Adv. Eng. Mater. 5, 787 (2003). http://dx.doi.org/10.1002/ adem. 200300359

[28] K. J. A. Raj and B. Viswanathan, Indian J. Chem. 48A, 1378 (2009). http://nopr.niscair.res. in/handle/123456789/6124

[29] J. Arbiol, J. Cerda, G. Dezanneau, A. Cirera, F. Peiro, A. Cornet and J. R. Morante, J. Appl. Phys. 92, 853 (2002). http://link. aip.org/link/?JAP/92/853/1

[30] H. Zhang and J. F. Banfield, J. Mater. Chem. 8, 2073 (1998). http://dx.doi.org/10.1039/A802619J

[31] H. Zhang and J. F. Banfield, J. Phys. Chem. B 104, 3481 (2000). http://dx.doi.org/10.1021/jp000499j

[32] P. I. Gouma and M. J. Mills, J. Am. Ceramic Soc. 84, 619 (2001). http://dx.doi.org/10.1111/j. 1151-2916.2001.tb00709.x

[33] F. Akbal, Environ. Prog. 24, 317 (2005). http://dx. doi.org/10.1002/ep.10092

[34] J. Yao and C. Wang, Int. J. Photoenergy 2010, 643182 (2010). www.hindawi.com/journals/ijp/ 2010/643182/

[35] R. I. Bickley, T. Gonzalez-Carreno, J. S. Lees, L. Palmisano and R. J. D. Tilley, J. Solid State Chem. 92, 178 (1991). http://www.sciencedirect. com/science/article/B6WM2-4B6NWG7-F7/2/21faed $756 \mathrm{bc} 30 \mathrm{f} 5 \mathrm{acf} 3966 \mathrm{ea} 0 \mathrm{fdb} 6 \mathrm{e} 4 \mathrm{e}$

[36] D. C. Hurum, A. G. Agrios, K. A. Gray, T. Rajh and M. C. Thurnauer, J. Phys. Chem. B 107, 4545 (2003). http://dx.doi.org/10.1021/jp0273934

[37] V. Collins-Martínez, A. Lóez Ortiz and A. Aguilar Elguézabal, Int. J. Chem. React. Engin. 5, (2007). http://www . bepress . com/ijcre/vol5/A92/

[38] R. A. Spurr and H. Myers, Analytical Chemistry 29, 760 (1957). http://dx.doi.org/10.1021/ ac60125a006 